\title{
MEMORY COMPATIBILISM: PRESERVING AND GENERATING POSITIVE EPISTEMIC STATUS*
}

\author{
Tiegue Vieira Rodrigues** \\ https://orcid.org/0000-0001-6011-4788 \\ tieguevieira@gmail.com
}

\begin{abstract}
The contemporary epistemological debate regarding the epistemic role of memory is dominated by the dispute between two different views: memory preservationism and memory generativism. While the former holds that memory only preserves the epistemic status already acquired through another source, the latter advocates that there are situations where memory can function as a generative epistemic source. Both views are problematic and have to deal with important objections. In this paper, I suggest a novel argument for granting memory the status of a generative source of justification and knowledge that overcomes objections raised for both preservationism and generativism. I shall call this view Memory Compatibilism. I argue that the proposed view better explains the generative epistemic character of memory.
\end{abstract}

Keywords Memory, Knowledge, Justification, Preservationism, Generativism.

RESUMO O debate epistemológico contemporâneo acerca do papel epistêmico da memória tem sido dominado pela disputa entre duas visões diferentes: o preservacionismo da memória e o gerativismo da memória. Enquanto o primeiro sustenta que a memória apenas preserva o status epistêmico já adquirido via outra fonte, o último defende que existem situações em que

** Universidade Federal de Santa Maria - UFSM. Santa Maria, RS, Brasil. 
a memória pode funcionar como uma fonte epistêmica geradora. Ambas as visões são problemáticas e têm de lidar com objeções importantes. Neste artigo, sugiro um novo argumento para conceder à memória o status de fonte geradora de justificação e conhecimento que supera as objeções levantadas contra o preservacionismo e o geracionismo. Chamarei esta visão de compatibilismo da memória. Argumento que a visão proposta melhor explica o caráter epistêmico gerativo da memória.

Palavras-chave Memória, Conhecimento, Justificação, Preservacionismo, Geracionismo.

\section{Introduction}

Memory is undoubtedly a central component of cognition and a main source of knowledge and justified belief. It has also motivated a fruitful and insightful debate. Almost everything that we believe at any given time, whether correctly or incorrectly, depends upon memory. It is hard to see how one could survive without memory. However, although we recognize the central aspect that memory occupies in our lives, telling what is the epistemic role of memory has proved to be a difficult task.

The usual way epistemologists approach memory is by drawing an analogy with some other knowledge sources. Among other uncontroversial epistemic sources are perception, testimony, inference, introspection (sometimes called 'consciousness'), and reason (sometimes called 'intuition' or 'rational insight'). Philosophers usually divide these sources into two distinct groups, namely, the basic sources and the non-basic sources. A basic source is basic in virtue of its capacity of yielding knowledge without positive dependence on the operation of some other source of knowledge (or of justification). A non-basic source is, consequently, a source that cannot yield knowledge (or of justification) without positive dependence on some other source. An analogy with other sources would help to determine whether a memory is a basic or non-basic source of knowledge and justification. Therefore, if one believes that memory is similar to perception, she would say that it is a basic source; on the other hand, if one believes that it is more similar to testimony, one would say it is a non-basic source. However, whether a source is basic or non-basic is a matter of controversy, especially when it comes to memory.

The contemporary epistemological debate about memory splits between two opposing views that have been motivated by the distinction just mentioned. 
Some philosophers maintain that memory only preserves or retain the positive epistemic status acquired previously from another source; this view is popularly known as 'memory preservationism. ${ }^{1}$ Others contend that there are compelling situations where a person can first acquire a positive epistemic status for her belief by remembering; this view travels under the banner of 'memory generativism.' Thus, the contemporary attempt to determine the epistemic role of memory has been focused on the preservationism/generativism distinction.

In this paper, I argue for memory compatibilism. A novel argument is developed for conceiving memory as a genuine generative source of positive epistemic status. ${ }^{3}$ The argument for the epistemically generative character of memory relies on the idea that the human memory is able not only to preserve but also to generate positive epistemic status when it is the source responsible for acting actively in the creation of a support relation between a mental content ${ }^{4}$ and a belief. As will be shown, memory compatibilism account is explanatorily superior to its competitors.

In what follows I will first lay out some memory taxonomy. Next, I will present the preservationist and generativist views, and expose some important objections to them. Then, I will suggest in section 4 a compatibilist view that can offer a better epistemological treatment for memory. Finally, in section 5, I will make some further remarks on how memory compatibilism is able to preserve preservationists and generativists intuitions without inheriting their main problems.

\section{Types of Memory}

Philosophers usually distinguish three different kinds of memory: ${ }^{5}$ experiential (or personal), propositional (or factual) and practical (or procedural). Having an experiential memory is for a subject to remember not only what happened in a past moment but also to remember what it was like. Suppose that a burglar attacked my friend last year when my friend was leaving a fancy

1 Epistemic preservationism advocates include Malcolm (1963, pp. 230-1), Dummet (1994), Burge (1997, p. 47), Huemer (1999, p. 349), Goldman (2009, p. 323), Jackson (2011, pp. 569-70), Owens (2000, p. 156), and Plantinga (1993, p. 61).

2 See Audi (1995), Bernecker (2009, pp. 96-103), Fernández (2016), Lackey (2005; 2007; 2008: app.), Malmgren (2006, p. 238), Michaelian (2011), and Pollock (1974, p. 193).

3 I am following DeRose (2009) and considering that the positive epistemic status of a subject is a property, whichwhich by virtue of having it in a sufficient amount, someone could be said to have Knowledge or Justified Belief. Moreover, of course, it is a property whose character is to be truth-conducive.

4 "Mental content" here should be understood broadly as a belief or just a raw content from sense experience.

5 See also Malcom (1963), Atkinson and Shiffrin (1968), Tulving (1972; 1985), Bernecker (2011), and Werning and Cheng (2017) for more memory taxonomy and important distinctions. 
restaurant and that he told me so. Today I remember that a burglar attacked my friend last year when he was leaving a fancy restaurant, and the memory I have is clearly not experiential because I obviously have not experienced the burglary. As a result, we can see that the experiential memory has two distinctive features. First, a subject can only experientially remember something that was personally experienced by her - experiential memory is restricted to cases in which the subject's claim to remember something is incorporated by the claim of having experienced it for herself. A second aspect concerns how experiential memory is represented; it involves both the remembered content (from a first-person perspective) and the qualitative experiences and imagery. Having an experiential memory, such as 'I remember leaving the restaurant hungry', consists in the evocation of parts of the original experience, allowing me to relive the original situation by going over what it was like (for instance, to feel hungry).

Another different kind of memory is the propositional memory, which is the memory of true propositions or facts. Roughly, propositions are abstract objects understood as the primary bearers of truth-value, and the content of our beliefs (i.e. what is believed, doubted, expected, feared, etc.). In this sense, the propositional memory is accompanied by a presupposition of the intentional object's factiveness to which the state referred to by "remember" is directed. So, if I remember that John Lennon was assassinated in front of the Dakota building, then I must have formed such belief in some moment prior to my remembering it, and it must be the case that John Lennon was actually assassinated in front of the Dakota building. Otherwise, how could I remember such a fact if it had not taken place? One cannot remember that $p$ if one has just learned that $p$; the same way one cannot remember that $\mathrm{p}$ if $\mathrm{p}$ is not the case. Unlike experiential memory, propositional memory does not restrict itself to one's qualitative experience and imagery; that is, one is not limited to things with which one has had previous direct or personal contact - this is why I can remember that John Lennon was assassinated in front of the Dakota building without having any experience of this event. One important aspect of both propositional and experiential memory is that the information (or content) that memory provides was acquired and stored in an appropriate way, at some previous time. ${ }^{6}$

6 I used the expression 'memories provide a subject with information' because is not uncontroversial whether memory 'represent' facts, or past events, to the subject. Although the standard position is to see memory as representing facts, or past events, some I argue (Debus, 2008) that we shouldn't think of experiential memories as of representations at all. It is no place to argue for this here, but the terminology used should help us to remain neutral on this point. 
Practical memory is still another kind of memory identified by philosophers. While propositional and experiential memory have in common that both seek (to some extent) to represent the word and that their content can in principle be articulated, practical memory is isolated, since such features cannot be applied to it. Having a practical memory of something is to remember how to do something; the practical memory is responsible for storing our previously acquired skills such as our ability to ride a bike, to drive a car, to swim, to play an instrument, etc. In order to remember how to drive, a subject does not need to be mentally able to evoke a list of instructions or to describe what it is like to drive; all the subject need to do is actually to drive.

\section{Memory Preservationism}

What is the epistemic role of memory? Is it merely a preservative source of knowledge and justified belief or it also works as a generative source? According to received wisdom in contemporary epistemology, memory is only a preservative source of knowledge and justified belief. Memory is only able to preserve (or retain) the epistemic status of a belief that was already acquired through another source. Advocates of preservationism claim that the epistemic role played by memory is strikingly similar to that of testimony. First, none of them is conceived as capable of producing new epistemic status. In particular, while testimony transmits knowledge and justification from a subject to another, memory preserves knowledge and justification over time for the same subject. That means the proposition believed by the subject must have been known or justified by a different source (than memory and testimony, respectively) at the moment it was acquired. For instance, if I have a known or justified memorial belief that the deadline for this paper is March 1, then I must have acquired this belief in a non-memorial way at some moment in the past, and its epistemic status dates from that moment.

Another important implication of preservationism, besides being unable to produce new epistemic status, is that it is also incapable of improving the epistemic status displayed by a belief at the time it is recalled ${ }^{7}-$ if the epistemic status of my belief was originally .8 , then it will be no greater than .8 at the time I recall it. Memory, thus, is unable of making an unknown proposition known, an unjustified belief justified, or an irrational belief rational - it can only preserve what is already known, justified or rational (Bernecker, 2011).

7 It is worth stating that preservationism allows for a decrease in justification. 
Following this view, Dummett says that "Memory is not a source, still less a ground, of knowledge: it is the maintenance of knowledge formerly acquired by whatever means" (Dummet, 1994, p. 262, emphasis in the original). In the same spirit, Owens says, "If a belief is irrational when adopted, it remains just as irrational while laid up in memory" (Owens, 2000, p. 156).

Preservationists over the time have relied upon the notion that memory is a repository where information is stored and kept available for being used when needed. There are several metaphors (much of them related to technology) used to represent remembering as being essentially a matter of storing and retrieving fixed items of information (Michaelian, 2016). Throughout the history, philosophers perceived memory as analogous to warehouses, libraries, archives, photographs, films, holograms, and so on. If the epistemological character of memory is only to preserve the original positive epistemic status of beliefs, then one could fairly request an explanation on how memory actually preserves such epistemic status. To answer this question, it is fruitful to consider how epistemic justification is to be conceived. According to one approach, epistemic justification is entirely a matter of internal (Conee and Feldman, 2004) or conscious justifying factors. ${ }^{8}$ Consider the following case. Imagine that I am a member of the jury on a trial and that I was presented with an evidential set of propositions e, which I believed, that actually confers positive epistemic status to the proposition that the subject is guilty, and let us assume that the subject is in fact guilty. When asked by the judge I readily asserted that the subject is guilty (based on the evidence e I just believed). In this case, my belief that the subject is guilty was epistemically justified by the evidential set $e-$ my justification for believing that the subject is guilty was due to both internal and conscious factors. According to this view of epistemic justification, my forthcoming memory that the subject is guilty will be justified for me only if I still (internally) have stored evidence $e$, and $e$ is consciously accessible for me.

A first objection one can raise for this internalist version of preservationism is the fact there is an abundant amount of justified beliefs stored in memory, for which there are no internal or conscious justifying factors. Maybe this is so because they were (irretrievably) forgotten, or maybe because they were substituted, defeated or underwritten by new ones, or maybe because there are other factors that are simply preventing one from remembering (maybe one is too nervous, or traumatized). Imagine further (taking up the previous example),

8 The psychological literature on metacognitive signals could be used by accessibilists to argue that there is subpersonal evidence available to back up many of our memory beliefs. Unfortunately, most internalists about memory are ignorant of the psychological literature on metacognition. 
several years after being a member of a jury in a murder trial, the case has been reopened and a lawyer shows up at my door making me questions. After some minutes of talking, I claim that the subject is guilty (keeping my original statement). The lawyer then asks how I know this. My immediate response is to say that I remember it. However, to say this is simply to classify the epistemic status of my belief as memory knowledge (or justified memory) as opposed to just having learned about the operation. When the lawyer asked me, "how do you know it?" he was actually requesting for the evidence that justified my belief in the proposition I just remembered (that the subject is guilty). To properly answer this question, I must appeal to the evidence $e$. Nevertheless, since too many years have passed I am no longer in a position to access (internally or consciously) $e$ - let's say because $e$ was irretrievably forgotten. If this is correct, then internalists are stuck with the very questionable outcome that the retained beliefs are justified only if the past (or original) evidence is also recalled.

In order to avoid this objection some advocates of preservationism embrace what is known as the principle of continuous justification (PCJ): S's belief from $\mathrm{t} 1$ that $\mathrm{p}$ is continuously justified for $\mathrm{S}$ at $\mathrm{t} 2$ only if $\mathrm{S}$ continues to believe that $\mathrm{p}$ (at $\mathrm{t} 2$ ) - even if $\mathrm{S}$ lost his original justification and has acquired no new justification in the meantime. ${ }^{9}$ While Pappas (1980) has argued that PCJ is a kind of basic or foundational justification, others (Burge, 1997; Owens, 2000) have appealed to PCJ in holding our memory beliefs because in the absence of defeaters we are entitled to believe what memory 'serves up' to us. The problem is to give an adequate explanation of how this conviction can actually provide any positive epistemic status.

The next objection to preservationism illustrates how a narrow conception of memory can be negative. Huemer (1999) argues that if S is justified to adopt the belief that $\mathrm{p}$, then $\mathrm{S}$ is justified in retaining it: the normal functioning of memory, in the absence of defeaters, constitutes an epistemically acceptable manner of retaining beliefs. It is not obvious that to be justified in believing amounts to be justified in retaining a belief. The problem with this view is the assumption that the mere fact of forming a justified belief is enough for it to automatically be stored into long-term memory (LTM), ${ }^{10}$ but that is false, memory just doesn't work like that. For instance, I could have justifiedly believed that someone is using the bathroom because the door is closed, but this belief could have lasted only a few seconds and have never entered into LTM. In this case, although I have had justification for believing that someone is using the 
bathroom I may not have stored this belief because this information was only available for short-term memory (STM) - since I haven't rehearsed or refreshed it, or it was irrelevant, it never came to enter LTM. Acquiring a belief (in the sense of forming a belief) and retaining it on memory are two distinct processes that cannot be conflated, I cannot leave aside the way memory actually works - although the discussion is epistemic, which may suggest that memory only retain beliefs, the retention of information by memory is much richer and is not exclusively epistemic.

Another objection I raise for preservationism is the fact that it cannot properly account for the difference between the attitude to remember and the propositional attitude to believe. That is, they cannot explain the difference between remembering $p$ from believing $p$. It seems that most preservationists just take the model used to explain how a belief is justified and (re)apply it to explain how a memory (a remembered proposition) is justified. ${ }^{11}$ But that just seems wrong. They seem to conflate the belief's acquisition (or formation) context with the belief's retrieval context. In order to form a belief in a given proposition and retain it, the subject needs justification, usually understood as the evidence available for the subject's evaluation. However, there is no good reason to suppose that for the retrieval of a belief, via memory, one would require satisfying the same requisites for its formation. If that were the case, then it would be no longer adequate to require the subject to have access (internally or consciously) to his evidence.

\section{Memory Generativism}

According to generativism, memory is a basic source of knowledge and justified belief - for it can produce new justification for some previously believed proposition. They also claim that a memory belief can be justified even if the original belief was not justified. Audi (1995) and Pollock (1974) advocate for a kind of phenomenology of recalling that is able to generate justification for a recalled belief.

One way they have argued is to consider memory as analogous to perception: in the same way that I am justified in my perceptual belief that the wall is red (based on something that I am 'appeared to'), I am also justified in my memorial belief that Tom's car is red based on this phenomenal state (of remembrance). The

11 It is far from obvious that a theory of justification - that is meant to be applied to the propositional attitudes of believing and knowing - will uncontroversially fit remembering since memory does not have propositions as itis only content. 
basic idea is that if $\mathrm{S}$ bases her belief that $\mathrm{p}$ on her state of seeming to remember that $\mathrm{p}$ and in the absence of defeaters, then $\mathrm{S}$ is prima facie justified in believing that $p$ is the case. Audi goes further and proposes that we should combine an internalist theory of justification with an externalist theory of remembrance and knowledge, in a way that my remembering that $\mathrm{p}$ would be justified because it was the product of a reliable source (memory). He argues that, in some cases, even when my memory belief that $\mathrm{p}$ is confronted with (misleading) defeaters that can make me unjustified in believing that $p$, I could retain my belief in $p$ due to my memorial process. Audi (1995, p. 39) says that in this case "my belief is, as it were, instinctual - which helps to explain why it survives my second order disapproval of it as unjustified." Audi's and Pollock's view suggests that memory is able to produce or generate new justificatory factors, new evidence.

The most obvious objection to this view is the highly counter-intuitive result that, by the simple fact of evoking a proposition, I would be able to increase its degree of justification. An even worse result is the case where I originally and unjustifiedly believed that $\mathrm{p}$ but, by remembering it, I would be able to yield a positive epistemic status for $\mathrm{p}$, up to the point it would become justified. McGrath (2007, pp. 12-22) already noticed this problem, he called it the epistemic boost problem: it is very suspicious to suppose that, all else being equal, a belief that is frequently retrieved will enjoy a better epistemic status than a belief that is rarely retrieved. There seems to be no clear parallel between the positive epistemic status of a belief and the number of times one retrieves it.

Another problem for generativists - even granting that there is a distinctive phenomenology for all beliefs that are remembered ${ }^{12}-$ is that it is not obvious that this 'instinct', or 'sense', or 'feeling', or 'seeming' to remember is able to do the epistemic work assigned to it. Let me illustrate my point by offering a slightly different example from Audi (1995, p. 38). Imagine that I have the firm belief that I have met you before. Nevertheless, for fun, you presented me plausible arguments, and bring forward testimony by a mutual friend (also amused by deceiving me) to show that we did not meet. It is possible you convince me by your evidence that the rational thing for me to do would be no longer to believe that I have met you before. However, losing the memorial sense that I have met you and drawing such conclusion is compatible with my simply being unable to help to continue to believe that I have met you before. Audi claims that, in this case, it might turn out that I remember meeting you, that I believe, on the basis of a reliable process, that I have met you before, and yet that I still 
do not have adequate justification from any accessible grounds for it. ${ }^{13}$ It is very hard to see in this case how I can still hold my belief that I have met you before, even if appealing for a reliabilist approach. If the evidence presented to me is enough to make me no longer believe that I met you, it is because it was sufficient to defeat whatever positive epistemic status conferred to the belief by the reliability of my memory, and, in this case, I would no longer have the sensation that I met you. The only way Audi could save his claim would be to say that this 'instinct' ('sense', 'feeling' or 'seeming') to remember is what justifies my belief that I have met you before, but then it would be hard to argue that they can actually provide any epistemic basis for believing it - no more than a prejudice can epistemize a belief.

There is also a moderate version of generativism (cf. Lackey, 2005, 2007; Bernecker, 2009, 2011). Advocates of this view agree with preservationism in that the act of remembering (the memory process) is unable to produce or generate new positive epistemic status or evidence. Since they agree that memory cannot make justification and knowledge from nothing, the only way that memory can be thought of as a generative source is by "removing defeaters and thereby unleashing the positive epistemic status that was already present when the belief was originally acquired" (Bernecker, 2011). The problem with this approach is that memory is not a generative source of epistemic status after all since all the epistemic status that is being unleashed by the removal of defeaters was already present and is independent of memory.

Lackey presents other cases that do not rely on forgotten memory, the following example rests on the idea that memory can generate justified belief by generating belief:

Inattentive Driver: While driving to work Clifford sees construction on the road but because his attention is elsewhere he doesn't come to believe that there is construction on the road. The visual information about the construction on the road is processed and stored in a non-doxastic (image-like) format. Yet later, when asked by a friend whether there is construction on the road Clifford comes to believe by memory that there is construction on the road. Given that belief is a necessary condition for justified belief (knowledge), Clifford acquires a new justified belief (knowledge) when he recalls what he saw while driving. ${ }^{14}$

13 Here, Audi seems to face the same problem that Sosa deals with Norman's case objection proposed by Bonjour (1980), that is to say that Norman's belief is an instance of Justified Belief (or knowledge) because it is the product of a reliable processes (namely, 'the clairvoyance'), even though Norman himself does not believe in it.

14 Taken from Bernecker and Grundmann (2017). 
With this example Lackey goes a little further and appeals to a beliefgeneration argument: a subject might acquire some information without forming the corresponding belief; if she comes to believe the information in question when she later retrieves it, and if the overall belief-forming process is reliable, then the resulting belief will be justified; memory, therefore, can generate justification. What this and other examples show is that memory can generate justification by generating belief or by lifting justificatory elements that were previously suppressed by defeating evidence.

One important objection to Lackey's account is that her example shows only that memory can generate ultima facie justification if a source other than memory has provided prima facie justification. ${ }^{15}$ In Clifford's case, the prima facie justification is supplied by sense experience. ${ }^{16}$ Moreover, the only lesson that can be learned from lackey's case is the fact that episodic memory can not only work as a source of prima facie justification but it can also be a source of doxastic generation. However, as already noticed by Bernecker (2009, p. 99) and Senor (2007, p. 199), this lesson is not of much interest since a subject may form a belief based on episodic memory without forming it on the basis of semantic memory; thus, the view that episodic memory can generate belief seems to be obvious.

Bernecker and Grundmann (2017) offered a new argument for epistemic generativism about memory, which relies on the idea that the human memory not only preserves but also modifies and edits the stored information. They rely on a principle called content abstractionism, according to which the content of the belief fed into the memory process may outstrip the content of the belief produced by the memory process. They also rely on two distinct phenomena. On the one hand, there is the phenomenon of incomplete memory, which assumes that, frequently, the content of a belief retrieved from memory is informationally impoverished vis-a-vis the stored content. On the other hand, there is the phenomenon known as "leveling," which refers to the loss of details, the condensation of elements, and the general simplification of the information encoded in memory.

Consider the following case presented by Bernecker and Grundman (2017) to support their view:

Seat Counter: Jim is sitting in the middle of a large, oddly shaped movie theater waiting for the show to start. To pass the time he decides to figure out how many people can

15 A belief is prima facie justified if it attains the level of justification which, in the absence of undefeated defeaters, is sufficient for its being ultima facie justified.

16 See Bernecker and Grundmann (2017) and Senor (2017) for a similar point. 
be seated in the theater. He counts the number of seats in the front row and the number of rows. Due to the dim lighting in the theater, Jim can't be certain that he correctly counted the number of seats in the front row and that every row has the same number of seats as the front row. Then he multiplies the two numbers. On the basis of a rough calculation, Jim comes to believe that the theater has 660 seats. As a matter of fact, there are 660 seats. But Jim is lucky in that he could have easily miscounted the seats in the front row as well as the number of rows. Also it just so happens that every row has the same number of seats as the front row (the row he based his rough calculation on). A few weeks later, Jim has forgotten the exact number of seats in the theater but still remembers that the theater has more than 500 seats. On the basis of his memory, Jim comes to believe that the theater has more than 500 seats. ${ }^{17}$

According to them, Jim's first belief that the theater has 660 seats is not a case of knowledge (or justified belief) because it was not formed by a reliable process (counting poorly and rough calculation). However, in a later time, when Jim forms the belief that the theater has more than 500 seats, he knows it (or is justified in believing it) because his memory is being reliable in accessing the remained content of his previous belief and in using it to form another belief. In the case at hand, it is the incompleteness of the memory process that functions as a corrective for potential errors made in the formation of the belief fed into the memory process. In the close possible worlds in which Jim is not so lucky as to correctly count the number of seats in the theater, his incomplete memory still gives rise to a veridical belief. So, by weakening the content of the initial belief, the memory process is able to rectify mistakes made in the formation of that belief.

One objection to this view is that even granting that the phenomenon of incomplete memory is true, it is not clear in which cases there is an actual content loss - it is not obvious (it is actually implausible) that in every single case there is a content loss. So, why should we assume that in this case what actually happens is a content loss instead of an inference being made from the original formed belief?

Another objection to this view is to say that the phenomenon of incomplete memory does not apply to beliefs (or propositional memory) but only to episodic memory or raw contents of experience. Imagine that I form a belief that I had eggs and toasted bread for lunch based on my perceptual experience of preparing and eating the breakfast. However, there were only eggs, I hallucinated the toasted bread. In this case, I would not be justified (or have knowledge). A week later, I form the belief that I have had eggs for breakfast. According to this view, this belief would be justified (or a case of knowledge) because 
- given incomplete memory - by weakening the content of the initial belief, the memory process is being able to rectify mistakes made in the formation of that belief. The problem with this is that if I kept both beliefs, the original belief and the later one, it would be hard to say that the latter belief is justified by memory - since I kept the original belief, there is no sense in talking about incomplete memory, it seems just a general case of inferential justification (or knowledge). But, conversely, if I lost or forgotten the original belief, how could it play the role they are assuming it to play? If I forget or lose a belief, I forget and lose all its content. So, there would be nothing more than I could rely on, and the phenomenon of incomplete memory would not be of much work here. ${ }^{18}$

An additional objection could still be raised to this account. It appears that it suffers from the same problem that Lackey's account does, namely, that memory can generate ultima facie justification if a source other than memory has provided prima facie justification. In Seat Counter, the prima facie justification is supplied by sense experience, even if it was originally acquired in an unreliable manner.

Fernández (2016) also advocates for a generativist approach that claims a strong form of memory generativism. He proposes a certain conception of mnemonic content according to which the content of an episodic memory is a self-referential belief in a proposition that originates when one engages in the act of remembering, and this mnemonic content is a new content that was not available before the remembering. The self-referential proposition is on the form ' $\mathrm{M}$ causally originates in my having perceived a certain object through $\mathrm{P}$,' where ' $\mathrm{M}$ ' refers to my episodic memory and ' $\mathrm{P}$ ' refers to a past perceptual experience. The generative aspect of his approach is that this new mnemonic content (the self-referential believed proposition) generated by memory is responsible for epistemizing the memorial belief.

One important objection that can be raised against Fernández's approach is that the assumption that, every time we have an episodic memory, it originates a self-referential believed proposition is highly implausible. In fact, this selfreferential believed proposition seems to be a second-order belief about his act of remembering and about the reliability of the source that originated the content

18 According to my view - which will be presented in next section - what is actually happening in such a case is that my experience of preparing and eating breakfast gives rise to a percept (an informational content that is stored in my memory), an episodic memory; and, based on this percept, I form the original belief that I had eggs and toasted bread for breakfast. The loss of content or information that the incomplete memory principle states only works for episodic memory, not for propositional memory. So, later when I form the belief that I had eggs for breakfast, this belief is based on the retained content of my episodic memory. Thus, forgetting or losing the original belief I formed wouldn't be a problem because my later belief is based on the episodic content I originally stored, and incomplete memory applies to this content. 
he is accessing through memory. Besides, the implausibility of populating the mind with unnecessary new entities every time one has an episodic memory (the self-referential believed proposition) results in the problem that such assumption has no practical evidence for it; when we remember episodic memories, there seems to be no proposition at all that is being generated or that should be generated by the use of this capacity.

Another objection to Fernandez's approach is that there is nothing, any particular mark, in the phenomenology of remembering that indicates the generation of such a self-referential belief. Moreover, if Fernández's approach were correct, it would be intuitive to assume that the same thing could be applied to other basic sources, such as perception, but that is not the case. It would be very implausible to assume that, every time I perceive something through a particular sense, it is being originated a self-referential proposition about it on the form " $\mathrm{P}$ causally originates in my perceiving a certain object through $\mathrm{M}$, where 'P' refers to my perceptual experience" and " $M$ " refers to the specific sense or method of perception.

\section{Memory Compatibilism}

The examples presented by Lackey, Bernecker and Fernández do not seem to exhaust the ways in which memory can be generative, although I do not think the cases they have provided satisfactorily reveal or explain the real and correct potential of memory as a genuine source of positive epistemic status, as I've indicated in the previous section. The point of this paper is to develop a new argument for a genuine form of epistemic generativism about memory. I am calling this view memory compatibilism because it preserves both preservatist and generativist intuitions, respectively, that in some situations memory can preserve positive epistemic status and, in others, it can also generate new positive epistemic status. Memory compatibilism, as it will be shown, is explanatorily superior to its competitors.

Before we move on to the analysis of some cases, it is imperative to explain some aspects of my view. Consider the situation where I form the belief that I had eggs and toasted bread for lunch based on my perceptual experience of preparing and eating the breakfast. My sense experience gives rise to a percept $t^{19}$ that is independent of the belief I have formed, in the sense that I would still have the percept if I have not formed any belief at all. However, the percept is, 
in general, not necessarily richer than any particular belief that could be formed on its basis. The percept, per se, is just a mental content (information that was stored in my brain), it is not itself a proposition, although it might encompass propositional content. In this sense, the percept, per se, is not true or false, it is just occurrent or non-occurrent, it is something I either possess or do not possess. In this sense, it is not quite appropriate to attribute justification to the percept, since it is, in fact, epistemically neutral. Justification, as it is understood here, is a property attributed to propositions or mental states which content is a proposition, such as beliefs.

Given the epistemic neutrality of the percept, my belief that I had eggs and toasted bread for breakfast is not justified simply because it is based on a percept (my sense experience of preparing and eating the breakfast). The percept here has no epistemic status (justification) to transfer to the belief formed based on it. So, the positive epistemic status of my belief (its justificatory character) is not being transferred from the percept; instead, the positive epistemic status emerges from the support relation that is being established between the percept and the belief. This support relation is not any relation, it is necessarily a reliable one, and its reliability is conferred by the source that is responsible for actually building such a support relation.

In this way, the justification for my belief that I had eggs and toasted bread for breakfast is not being transferred from the percept, instead, the justification for my belief emerges from the support relation established - in this case, by the source of perception - between the percept and my belief. Here, perception (conceived a source) is not only responsible for acquiring certain mental content from sense experience but also for acting actively in properly relating this content to a correspondent belief - in this case, perception is not only a causal source but also an epistemic source. A distinctive situation is one in which I have the experience of preparing some eggs and toasted bread, but it does not give rise to any individual belief, just to the percept. A few days later, I access, via memory, the percept that has been stored and, based on it, I now form the belief that I had eggs and toasted bread for breakfast. In this case, my belief is justified by memory, since memory is being responsible for appropriately relating the percept to a correspondent belief. Thus, memory is the proper source of justification, and not perception. While perception is the original (causal) source of the content acquired from experience, memory is the (epistemic) source which is actually generating positive epistemic status by way of relating the percept to the correspondent belief.

A further central clarification regards the distinction between the role that a source can play. On the one hand, a source (or whatever property or relation 
able to produce positive epistemic status) can be seen for its causal role, that is, regarding its function as a belief-producer, call it causal source. On the other hand, a source (or whatever property or relation able to produce positive epistemic status) can be understood according to its epistemic role, that is, according to its function of providing epistemic status for the subject's knowledge (or the grounds on which someone could be said to have knowledge), call it epistemic source. ${ }^{20}$ If we consider the vast majority of cases (the typical cases), then we will see that, usually, the causal source is also the epistemic source; however, these properties are not conceptually or analytically guaranteed to overlap. Therefore, a causal relation not always add or guarantee a positive epistemic status.

Now that I've laid out important clarifications about my approach, we can analyze some cases in light of it in order to see how memory is being genuinely generative of epistemic status.

Consider the following cases.

(Case 1) Imagine that by entering the classroom early in the morning, at t0, I perceive an image of the environment (which was properly registered in my cognitive system) and I noticed (believed) that some students were absent, that the lights were on, that Tom was wearing a blue t-shirt, etc. However, there were many other things also perceived by me but for which I did not form any particular belief, such as the open windows, the sleeping student, Jena's uniform, etc. After the class, I checked my emails. I received Peter's email apologizing for having slept in my class. At that moment (at t1), I did not remember having seen Peter sleeping but I justifiably believed that he was sleeping, based on his testimony. Later on (at t2), I was lying on my bed, waiting for sleep, when the image of the perceived environment come, via memory, into my mind and, based on it, I realized that Peter was really sleeping. So, now (at t2), my positive epistemic status for believing that 'Peter was sleeping' appears to have been increased by my recollection of the image of Peter sleeping.

(Case 2) Imagine that by entering the classroom early in the morning, at t1, I perceive an image of the environment (which was properly registered in my cognitive system) and I noticed (believed) that some students were absent, that the lights were on, that Tom was wearing a blue t-shirt, etc. However, there were many other things also perceived by me but for which I did not form any particular belief, such as the open windows, the sleeping student, Jena's uniform, etc. Later on (at t2), I was lying on my bed, waiting for sleep, when the image of the perceived environment come, via memory, into my mind and, based on it, I come to believe that Peter was sleeping.

In Case 1, I was justified to believe (at t1) that Peter was sleeping, based on his testimony. Later on (a t2), when the episodic memory (the image of Peter 
sleeping) comes into my mind, my previous belief - originally based solely on the testimony - is reassessed and readjusted in a way that my justification for believing that Peter was sleeping is now also based on my memory of having seen him sleeping (at t0). Memory is responsible for increasing the positive epistemic status of my original belief that Peter was sleeping. It is worth noting that justification is widely accepted by epistemologists as coming in degrees. To see how my memory of Peter sleeping (or the recollection of the image of Peter sleeping) is genuinely generating a positive (and prima facie) epistemic status for my belief that Peter was sleeping, consider the following case.

(Case $1^{*}$ ) Suppose that, the next morning (at $\mathrm{t} 3$ ) Peter sent me another email telling me it wasn't him who sent me the first email, Jena (his girlfriend) did it because she was fearing some kind of retaliation that I might apply to his boyfriend and tried to cleanse his image. In this new scenario, even though Peter's testimony was defeated by the new information, I would still be justified in believing that he was sleeping based exclusively on my memory (or recollection) of Peter's being sleeping.

In Case $1^{*}$, we have a scenario in which Peter testimony is defeated by new information (also testimonial), in such a way that the only thing that remains for supporting my belief is my memory (or recollection) of the image of Peter sleeping. Do now (at t3) I am justified (rational, or in a position to know) that Peter was sleeping? The intuitive answer seems to be 'yes'; I am still justified in believing that Peter was sleeping. In denying it, one has to deal with the implausible result of accepting that my memory of Peter's being sleeping can provide no positive epistemic status. Thus, even if losing the testimonial belief and, consequently, the epistemic status generated by Peter's testimony, I am still justified (at $\mathrm{t} 3$ ) in believing that Peter was sleeping, based just on my memory of him sleeping - because my memory is now being responsible for providing the positive epistemic status required for my belief. ${ }^{21}$

21 An Anonymous referee suggested that there is something amiss with the cases presented (cases 1, 2 and $\left.1^{*}\right)$ and that the cases were underdescribed. She/he argued that, and I quote, in case $1^{*}$, the second email does not defeat the belief that Peter was sleeping in class. Instead, it defeats another belief, call it T, the belief, entertained by the subject, that she received Peter's authentic testimony via email. This is clear from the way I described the case above, but not so much in the author's paper. For in case $1 \mathrm{~S}$ comes to believe in two propositions through the first email: Peter was sleeping in class (B), and she received that testimony from Peter himself, who was sorry $(T)$. The defeater makes her change the set of believed propositions $-T$ drops out but B remains: $S$ still believes that Peter was sleeping in class (B), but now also holds the new belief that she received this information through Jena instead of Peter, because Jena was afraid and so on $\left(T^{*}\right)$. Everything else being equal, Jena's and Peter's testimonies carry the same epistemic weight, that is why it still is intuitive to claim that $S$ is justified to believe that Peter was sleeping in class." This allegedly would undermine my conclusion that memory has improved S's epistemic support for B."

My answer to this is to say that the referee is making a mistaken assumption about the cases I presented; particularly, she/he is assuming that the subject would have to form a second-order belief about the testimony received (the belief helshe described as ' $T$ '). Of course, if we describe the case in a different manner, as 
Case 2 has important differences from Case 1. When, at t1, I perceived an image of the environment (more precisely, of Peter sleeping) and my cognitive system properly registered and stored such information, this information is not by itself epistemically relevant, since no application has yet been given to it, it is just collected information. ${ }^{22}$ However, at $t 2$, when the memory (the image) of Peter sleeping comes into my mind it causes me to believe that Peter was sleeping. Clearly, here the cause of my belief is my memory - memory is responsible for taking the image of Peter sleeping and generating (or creating) an epistemic relation of support for the belief (that Peter was sleeping), an epistemic relation that clearly was not there before (when the image was originally registered and stored). Here, although the content is not new, the relation established with it is. In Case 2, not only memory is generating positive epistemic status by creating the epistemic connection to the belief, but it is also responsible for producing the belief itself. Memory made the stored information epistemically relevant when gave to her an application. Thus, in Case 2, memory is causally and epistemically responsible for my belief that Peter was sleeping.

Applying the proposed approach in order to explain the cases presented by competitors' accounts can be a good way to see how it can be explanatorily superior. First, let us take Lackey's case. Case 1 is very similar to lackey's Inattentive Driver case; thus, the way we apply memory compatibilism to explain this case is analogous to how it was applied to explain Case 1. Clifford sees the construction on the road, and his cognitive system appropriately recorded this information. However, the perceived content does not give rise to any particular belief about the construction on the road. Here, the perceived content is epistemically neutral, so it does not have any positive epistemic

the referee does, we can have a different outcome, but then it is a different case after all. Moreover, it is not obvious that the subject in the case would form that second-order belief. For example, why would I form the belief in T (that I received Peter's authentic testimony via email)? For instance, suppose I believe that it is raining because I've heard something that sounds like the rain. Later on, Paul tells me that it has not rained and I believed what he said (let's say, because he is a reliable friend). It is hard to argue that, in this case, I formed the second-order belief that I've received Paul's reliable testimony; the belief I formed based on his testimony is just that it hasn't rained. Therefore, there is no reason to suppose that the subject, in the cases I offered, necessarily would have formed the (second-order) belief in $\mathrm{T}$, as suggested by the referee. My intention with these cases is to argue that memory is being responsible for supporting my belief that $B$, Peter was sleeping in class, and the referee's comment does not seem to change it. Initially, in case 1, my belief that $\mathrm{B}$ was being supported by the first e-mail I have received from Peter where he apologized for being sleeping was additionally supported from my memory of 'seeing' Peter sleeping. My point in cases 1 * and 2 is to call attention to the fact that even if I lost the support offered by the initial testimony (Peter's first email- which was actually Jenna's), I would still be warranted in holding my belief that B, based solely on my memory of 'seeing' Peter sleeping. It is worth mentioning that the discussion about defeaters here is not essential for my point.

22 Which ways of information acquisition count as "appropriate" will vary across different kinds of memories - as we already saw, in order for a subject to remember an event it is necessary that the subject witnessed the relevant event in the past, whereas this is not necessary in the case of factual memory. 
status to transfer. Consequently, later, when Clifford remembers having seen the construction on the road and based on it forms the correspondent belief, memory is being responsible not only for generating this new belief but for generating the epistemic status that emerges from this relation between the previous content and the correspondent belief. Memory, according to this account, is being responsible for genuinely generating positive epistemic status and not only causally producing a belief.

Memory compatibilism also seems to give a better explanation for what is going on in the Seat Counter case presented by Bernecker and Grundmann (B\&G). According to $B \& G$, when Jim forms his belief that the theater has 660 seats based on his experience of counting the number of seats in the theater, his belief is unjustified since counting poorly and rough calculation are unreliable belief-forming. I agree that Jim's belief is unjustified but the way I tell the story is a little bit different. Jim perceptual experience gives rise to a percept (a mental state with the content of his experience), and based on it he forms the belief that the theater has 660 seats. Here it is important to remember the distinction between an epistemic and a causal source. From the causal point of view, perception has adequately given rise to a mental state (the percept) and this content is epistemically neutral. However, in this case, perception was unable to work as an epistemic source since, when relating the content with the correspondent belief, it was unable to produce a proper support relation (a truth-conducive one). Later, when Jim forms the belief that the theater has more than 500 seats, this belief is based not on the previous unjustified belief that the theater has 660 seats, and the reason for that is that Jim does not have this belief anymore since he has forgotten it. Instead, Jim's belief that the theater has more than 500 seats is based on the content perceived by him that was appropriately stored. Given incomplete memory, this content may have decayed and does not contain anymore the information about 660 seats only the information that it is more than 500 seats. The belief that the theater has more than 500 seats is now justified, but it is not justified because the content of this sense experience is transmitting positive epistemic status, instead it is justified because memory, when accessing the perceptual content, appropriately relates it to the correspondent belief, and the epistemic status or justification for it is emerging from this relation that was created by the use of this capacity.

Once we have presented the compatibilism of memory and how it deals with some important cases, let us now anticipate some objections that could be raised against it, and answer them properly. A first objection that one could raise against memory compatibilism is that the faculty of memory does not genuinely generate the positive epistemic status (justification/ rationality/ knowledge) in 
question at $\mathrm{t} 2$, in case 2 . Instead, the positive epistemic status is generated by reason or perception, with the resulting positive epistemic status (justification/ rationality/ knowledge) being inferential (or perceptual) rather than memorial in character. Here one could invoke the same criticism that is raised against Lackey's Inattentive Driver's case and say that memory compatibilism is only able to provide ultima facie justification because prima facie justification is being supplied by sense experience. One could say that when I remember the image of Peter sleeping and this image produces my belief that Peter was sleeping, the positive epistemic status of my belief is conferred by my original perceptual experience of that visual image, which was used to infer that Peter was sleeping. My response is that this objection is mistaken and not applicable to memory compatibilism. In my view, sense experience, and in particular the perceptual content acquired through sense experience, is epistemically neutral since it is not necessarily propositional. There is a mistake to assume or attribute any epistemic character to this content. So, in T2, when I form the belief that Peter was Sleeping based on my episodic memory of remembering seeing him sleeping, the justification for this belief is not inherited from the content of sense experience, instead the epistemic status emerges from the perceptual content being appropriated related/connected with the correspondent belief via memory. Memory here is the source responsible for accessing the perceptual content and for creating the relation of support between the perceptual content and the correspondent belief, and the positive epistemic status, the justification, emerges from memory acting the way it is. In this sense, memory is responsible for actively generating the epistemic status (justification) that was not present before the use of this capacity.

In a further objection against Case 2, one could argue that work on attentional blindness, for example, would seem to count against it. ${ }^{23}$ In Simons' and Chabris' (1999) paper, even though in one sense subjects perceived the gorilla (and umbrella woman) they often did not notice the gorilla, and, further, in the experiments "not one of the eighty-eight non-noticers 'remembered' the Gorilla or Umbrella-Woman events when specifically asked about it, and several did not believe that the event had happened until the videotape was replayed for them" (Simons \& Chabris, 1999, p. 1072). My response would be to say that this work on attentional blindness is too limited to count as definitive. ${ }^{24} \mathrm{I}$ believe another

23 l'd like to thank an unknown referee for allowing me to make/making this point.

24 My point here is not to dismiss the study as invalid, but rather to argue that it is still plausible to maintain that the sensorial experience data about the gorilla was registered by the subject's cognition and could be retrieved through the adequate use of cues or guides. 
completely different result could be produced if the subjects would have been asked a day later (or sometime later) whether they remember noticing some strange event about the video or if they were given some other cues to access such information. It seems fair to say that if the information caused by my sense experience by watching the video did give rise to a mental state (of perception) about it, then, even if the gorilla was not immediately noticed, there is nothing that necessarily would prevent one to reexamine such mental state at a later time and come to realize that the gorilla was there (even forming a belief that the gorilla was there). Consider cases such as when you are focused reading a book or watching a movie and your wife (husband, or someone else) talks to you; some seconds or minutes later you realize that something happened even if you don't know exactly what it was. You then ask your wife, "did you say something?" Clearly, this example is also a case of attentional blindness, but here you were able to later realize something you have not noticed but clearly perceived.

A third objection is to say that memory compatibilism also faces the epistemic boost problem implicating that, every time one remembers a belief, its epistemic status is increased. This objection is also mistaken. Memory compatibilism does not imply the epistemic boost problem. If, in case 1, I had believed (at t1) that Peter was sleeping based on Peter's testimony and, later on, just remembered (at t2) that Peter was sleeping, then (everything else being equal) the act of remembering would not by itself have generated any positive epistemic status. This is so because, in this case, there would be no readjustment and no new connection regarding my original belief that Peter was sleeping; so, no new epistemic status is being generated. When memory takes a dormant proposition believed in the past (a non-occurrent belief) and makes it occurrent (conscious) in the present, it doesn't automatically mean that any positive epistemic status is being generated - to simply entertain a proposition can hardly be seen as providing it any positive epistemic status. Memory only generates positive epistemic status when it positively acts to generate or to establish new epistemic relations (previously absent) with the belief in question.

Still another objection is that memory compatibilism is also committed with the implausible result that if memory can generate positive epistemic status; then, previously irrational or unjustified beliefs could become rational and justified just by being remembered. This objection is false. The first part of the answer to this objection was already offered in response to the epistemic boost problem; that is, memory generates positive epistemic status only when it positively acts to generate or to establish new epistemic relations (for grounding beliefs) - epistemic relations that were previously absent. Suppose that despite 
possessing compelling evidence that indicates that Sr. Deadish committed the murder I've formed a belief in this fact based on my racial prejudice since Sr. Deadish is afro-descendant. In this case, my belief that Sr. Deadish committed the murder is unjustified. Imagine that years later I remember that Sr. Deadish committed the murder. Everything else being equal, memory here is not increasing or generating any new positive epistemic status since there is no new relation or property being created by memory. So, if my belief was previously unjustified, merely remembering it wouldn't automatically be enough to justify it. However, a completely different situation would be the case in which, by remembering the belief that Sr. Deadish committed the murder, I appropriately connect it with the compelling evidence that I already possessed but have not used before. Now my belief that Sr. Deadish committed the murder would be justified by memory since memory, in this case, would be responsible for creating the support relationships between the pieces of evidence I already possessed and the belief about Sr. Deadish. Again, it is important to bear in mind that the epistemic status that those pieces of evidence may have previously possessed is not being transmitted or inherited by the target belief; instead, the epistemic status for it is emerging from memory being appropriately connected with such contents.

\section{Conclusion}

In section 1, I've presented some important distinctions between kinds of memory that can be found in the philosophical literature in different contexts. Although these distinctions were not central to my argument, they certainly helped me to elucidate implicit aspects. In the subsequent sections ( 2 and 3 ), it was presented both of the dominant views regarding the epistemological role of memory, and it was also discussed important objections to them that significantly undermine their plausibility. After this, in section 4, I offered an original account of the genuine epistemological role of memory - which combines both preservationist and generativist intuitions in a compatibilist spirit - which is able to preserve their virtues without inheriting their main problems.

Contra epistemological dogma, memory compatibilism claims that memory should be categorized within the category of basic sources, such as perception; sources capable of providing us with fundamentally justified belief (at least prima facie) and knowledge. It agrees with preservationism that memory has the character, although not exclusively, of preserving the epistemic status acquired in the moment of a belief's acquisition. Nevertheless, it also agrees with generativism that memory can genuinely generate new epistemic status. 
The most important thing for setting memory compatibilism apart from the competing views is that it actually makes the case for a genuine generativist epistemological character of memory. Instead of focusing on the positive epistemic status as something generated by the contents previously produced by other sources, my approach was to appeal to the epistemic generative aspect of memory as something that can emerge when memory is active. By being active, memory uses such contents in order to reaccess and readjust the epistemic status of beliefs, thus generating and establishing new epistemic relations that were not previously available. Memory compatibilism uncovers what is distinctive about memorial justification and knowledge: memory not only has the capacity to preserve content and justified belief or knowledge, but it has also the capacity to generate these epistemic features in its own right.

\section{Acknowledgements}

Thanks to Sven Bernecker, Thomas Grundmann, Luis Rosa, Amy Floweree, Anna-Maria Eder, César dos Santos and an anonymous referee for helpful discussion and suggestions on this paper.

\section{Reference}

ATKINSON, R. C., SHIFFRIN, R. M. "Human memory: A proposed system and its control processes.” (Vol. 2, pp. 89-195). In: K. W. Spence, J. T. Spence (eds.). The psychology of learning and motivation New York: Academic Press, 1968.

AUDI, R. "Memorial Justification." Philosophical Topics, Vol. 23, Nr. 1, pp. 31-45, 1995. AUDI, R. "The sources of knowledge." In: Oxford Handbook of Epistemology, ed. P. Moser, 71-94. Oxford: Oxford University Press, 2002.

BERNECKER, S. "Memory: A Philosophical Study". Oxford: Oxford University Press, 2009.

BERNECKER, S. "Memory Knowledge". In: Routledge Companion to Epistemology. (eds.) S. Bernecker \& D. H. Pritchard, 326-34. Routledge: London, 2011.

BERNECKER, S., GRUNDMANN, T. "Knowledge from Forgetting". Philosophy and Phenomenological Research. (Online) 13 October 2017.

BERNECKER, S., MICHAELIAN, K. (eds.) “The Routledge Handbook of Philosophy of Memory”. Routledge, 2017.

BonJour, Laurence. 1980. "Externalist Theories of Epistemic Justification." Midwest Studies in Philosophy 5:53-73.

BURGE, T. "Content Preservation.” The Philosophical Review, Nr. 102, pp. 457-88, 1993. BURGE, T. "Interlocution, Perception, and Memory." Philosophical Studies, Vol. 86, pp. 21-47, 1997. 
CONEE, E., FELDMAN, R. "Evidentialism: Essays in Epistemology". Oxford: Clarendon, 2004.

COWAN, N. "What are the differences between long-term, short-term, and working memory?" Progress in Brain Research, Vol. 169, pp. 323-38, 2008.

DENNETT, D. C. "Content and Consciousness". London: Routledge and Kegan Paul, 1969.

DEBUS, D. "Experiencing the Past: A Relational Account of Recollective Memory." Dialectica, Nr. 62, pp. 405-32, sEEP 2008.

DEROSE, K. "The Case for Contextualism: Knowledge, Skepticism, and Context". Oxford University Press, 2009.

DUMMET, M. "Testimony and Memory." In: A. Chakrabarti, B. K. Matilal (eds.). Knowing from Words. Kluwer Academic Publishers, 1994.

FERNÁNDEZ, J. "Epistemic Generation in memory". Philosophy and Phenomenological Research, Vol. XCII, Nr. 3, pp. 620-644, 2016.

GOLDMAN, A. I. "Internalism, Externalism, and the Architecture of Justification," Journal of Philosophy, Nr. 106, pp. 309-338, 2009.

HUEMER, M. “The problem of memory knowledge." Pacific Philosophical Quarterly, Nr. 80, pp. 346-57, 1999.

JACKSON, A. "Appearances, Rationality, and Justified Belief". Philosophy and Phenomenological Research, Nr. 82, pp. 564-593, 2011.

LACKEY, J. "Memory as a Generative Epistemic Source". Philosophy and Phenomenological Research, Nr. 70, pp. 636-58, 2005.

LACKEY, J. "Why Memory Really is a Generative Epistemic Source: A Reply to Senor". Philosophy and Phenomenological Research, Nr. 74, pp. 209-19, 2007.

LACKEY, J. "Learning from Words: Testimony as a Source of Knowledge". Oxford: Oxford University Press, 2008.

MALCOLM, N. "Knowledge and Certainty". Ithaca: Cornell University Press, 1963. MALMGREN, A.-S. "Is There A Priori Knowledge by Testimony?". Philosophical Review, Nr. 115, pp. 199-241, 2006.

MICHAELIAN, K. “Generative Memory”. Philosophical Psychology, Nr. 24, pp. 323-342, 2011.

MICHAELIAN, K. "Mental Time Travel: Episodic Memory and Our Knowledge of the Personal Past". Cambridge, MA: MIT Press, 2016.

MCGRATH, M. “Memory and Epistemic Conservatism." Synthese, Nr. 157, pp. 1-24, 2007.

OWENS, D. "Reason without Freedom: The Problem of Epistemic Normativity". London and New York: Routledge, 2000.

PAPPAS, G. S. (ed.). "Justification and Knowledge: New Studies in Epistemology". Dordrecht: Reidel, 1980.

PLANTINGA, A. "Warrant and Proper Function". New York: Oxford University Press, 1993. 
POLLOCK, J. L. "Knowledge and Justification". Princeton: Princeton University Press, 1974.

RODRIGUES, T. V. "Knowledge from falsehood revisited." Veritas, Vol. 62, Nr. 3, pp. 705-724, 2016.

SENOR, T. D. "Preserving Preservationism: A Reply to Lackey." Philosophy and Phenomenological Research, Nr. 74, pp. 199-208, 2007.

SENOR, T. D. "Preservation and generation." (pp. 323-334). In: S. Bernecker, K. Michaelian (eds.). The Routledge Handbook of Philosophy of Memory. Routledge, 2017. SHOEMAKER, S. "Memory.” (Vol. 5, pp. 265-74). SEEP! In: P. Edwards (ed.). Encyclopedia of Philosophy. New York: Macmillan, 1967.

SIMONS, D. J., CHABRIS, C. F. "Gorillas in our midst: sustained inattentional blindness for dynamic events." Perception, Vol. 28, Nr. 9, pp. 1059-74, 1999.

TERONI, F. "The phenomenology of memory.” In: S. Bernecker, K. Michaelian (eds.). The Routledge Handbook of Philosophy of Memory. Routledge, 2017.

TULVING, E. "Episodic and semantic memory." (pp. 381-402). In: E. Tulving and W. Donaldson (eds.). Organization of Memory. New York: Academic Press, setep. 1972. TULVING, E. "Memory and consciousness." Canadian Journal of Psychology, Nr. 26, pp. 1-26. 1985.

WERNING, M., CHENG, S. “Taxonomy and Unity of Memory”, In: S. Bernecker, K. Michaelian (eds.). The Routledge Handbook of Philosophy of Memory. Routledge, 2017. 